\title{
Marination and post marination storage of shark (qualus megalops)
}

\author{
By
}

Merita Joseph

Thesis submitted to the University of Sri Jayewardenapura as the partial fulfillment requirement for the award of the degree of Masters of Food Science and Technology. 


\section{Declaration}

The work described in this thesis was carried out by me under the supervision of Dr. (Mrs.) Indira Wickramasinghe, Head of Department of Food science and Technology, Faculty of Applied Sciences, University of Sri Jayawardenapura. I declare that this report or any part of the report has not been submitted, presented or accepted in any previous applications for another degree.

1.8. $.0 .3 .2 .0 .14 \ldots \ldots$

Date

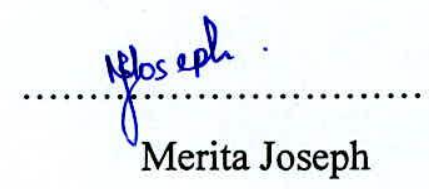




\title{
Declaration of the supervisor
}

I certify that the above statement made by the candidate is true to the best of my knowledge and that this thesis is suitable for submission to the University for the purpose of evaluation.

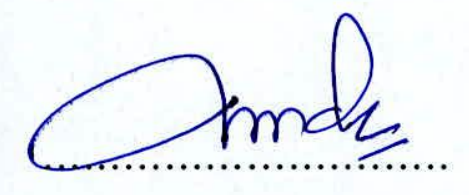

Supervisor

\section{$18 / 3 / 2014$ \\ Date}

\author{
Dr. (Mrs.) Indira Wickramasinghe, \\ Head of Department of Food science and Technology, \\ Faculty of Applied Sciences, \\ University of Sri Jayawardenapura \\ Nugegoda, \\ Sri Lanka.
}




\section{ABBREVIATIONS}

${ }^{0} \mathrm{C} \quad$ degree of Celsius

g gram

L Liter

$\mathrm{ml} \quad$ milliliter

$\% \quad$ percent

$\mu \mathrm{m} \quad$ micrometers

CFU Colony Forming Units

$\min \quad$ minutes

NA Nutrient Agar

$\mathrm{H}_{2} \mathrm{SO}_{4} \quad$ Sulphuric acid

$\mathrm{HCl} \quad$ Hydrochloric acid 


\section{TABLE OF CONTENTS}

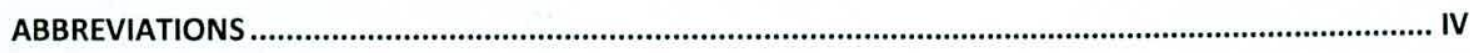

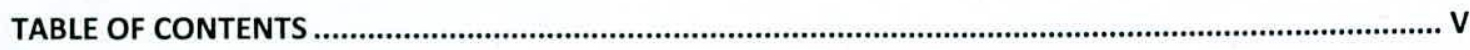

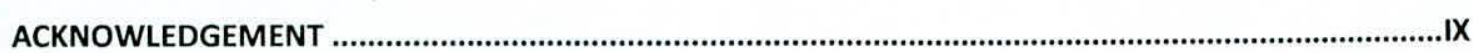

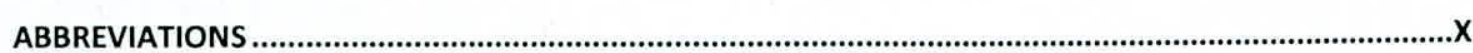

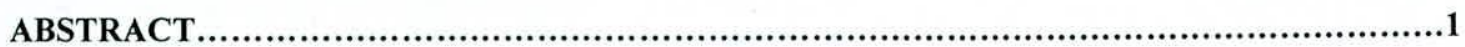

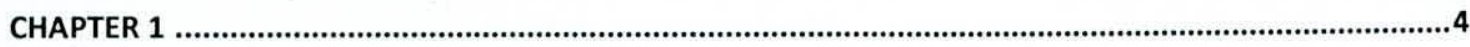

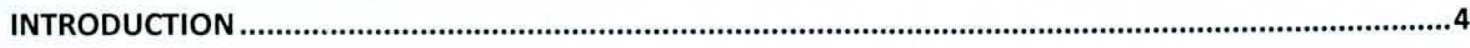

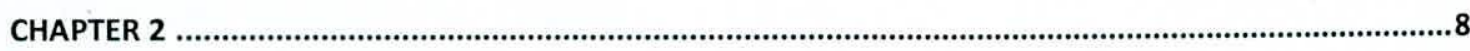

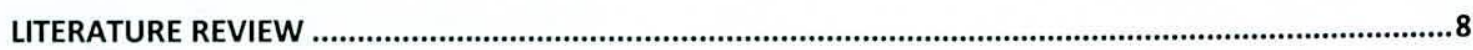

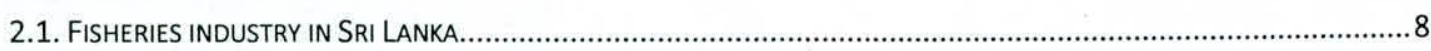

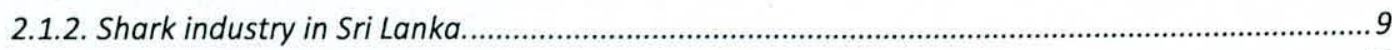

2.1.3. About the Squalus megalops ............................................................................................... 12

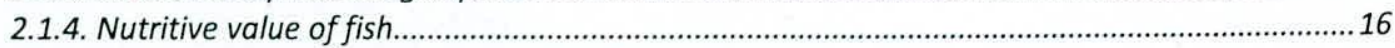

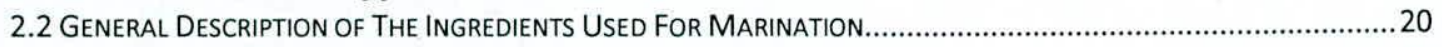

2.2.1. Pepper (Sinhala - Gammiris, Tamil-Aguttam, Arish, Milagu) ..............................................2 20

2.2.2. Turmeric (Sinhala- Ath Kaha, Kaha Tamil-Manjal)........................................................22

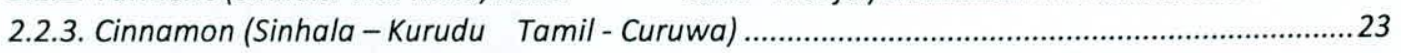

2.2.4. Cardamom (Sinhala-Karadamungu, Ensal Tamil-Anji, Elon) ................................................2 24

2.2.5. Garlic (Sinhala-Sudu-Iunu, Hela lunu Tamil-Vellavengayam, Vellaipundu)..........................26

2.2.6. Ginger (Sinhala- Inguru, Sidhinguru Tamil- Allan, Inji).........................................................27

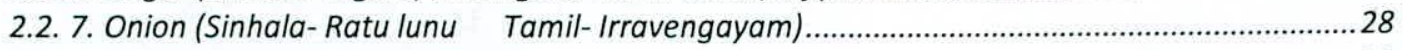

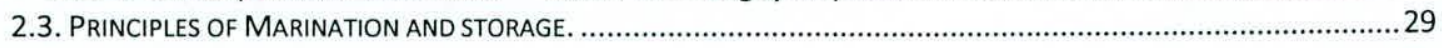

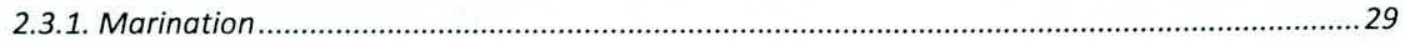

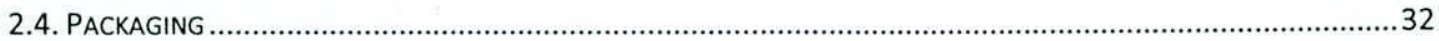

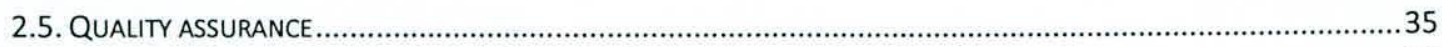

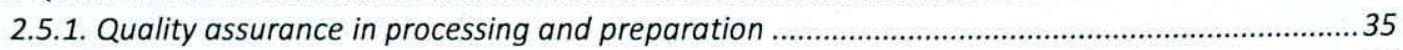

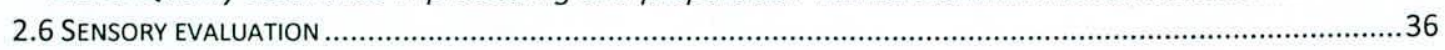

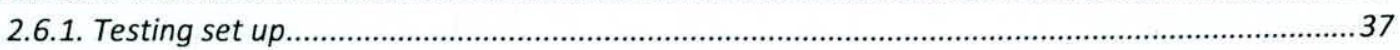

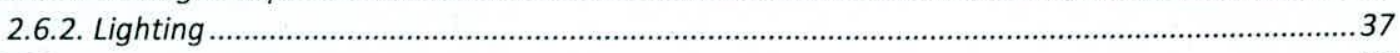

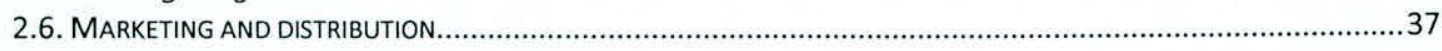

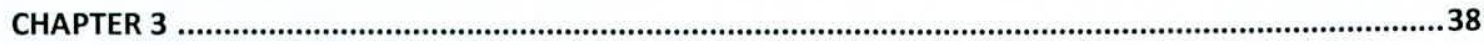

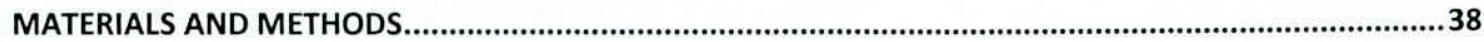

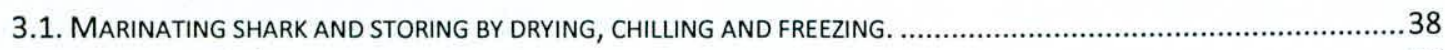

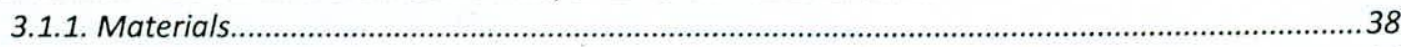

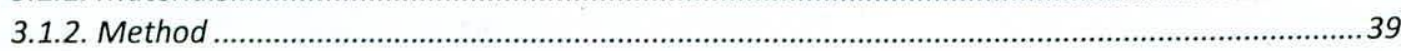

FOR SENSORY EVALUATION THE FRESH FISH AND THE MARINATED SAMPLES WERE STEAMED AND WERE EVALUATED BY 20

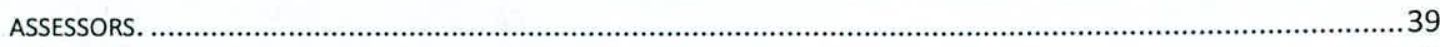

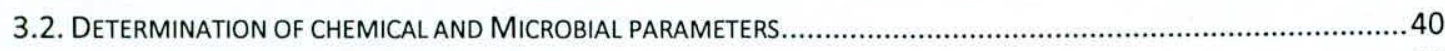

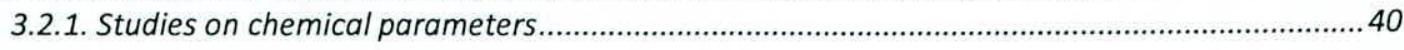




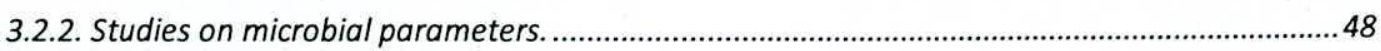

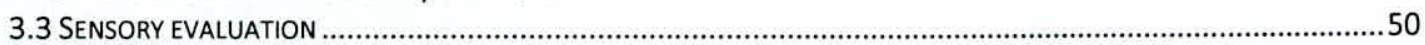

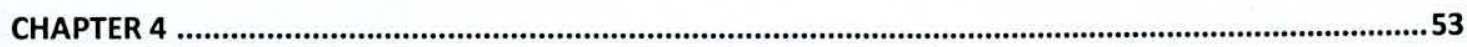

RESULTS AND DISCUSSION ..................................................................................................................53

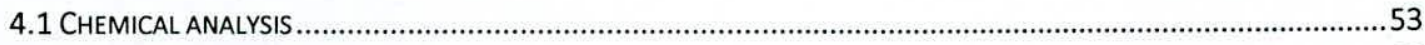

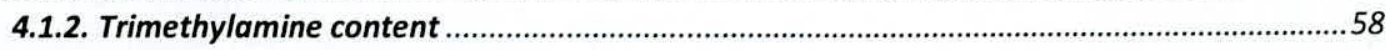

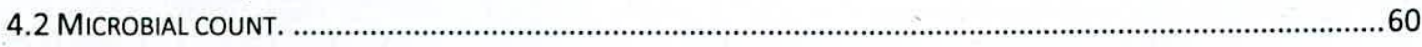

TABLE 4.6.TOTAL MICROBIAL COUNT IN MARINATED AND CHILLED FISH DURING THE STORAGE OF THREE MONTHS............61

TABLE 4.7. TOTAL MICROBIAL COUNT IN MARINATED AND FROZEN FISH DURING THE STORAGE OF THREE MONTHS. ...........61

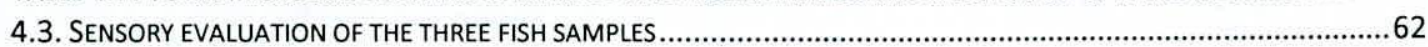

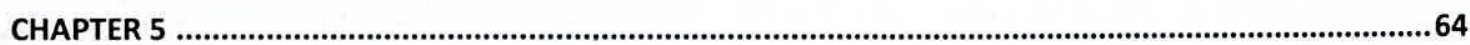

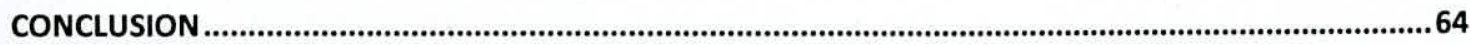

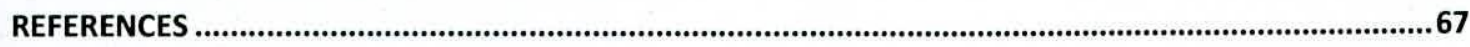

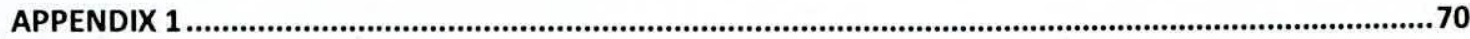

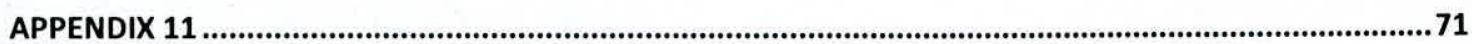

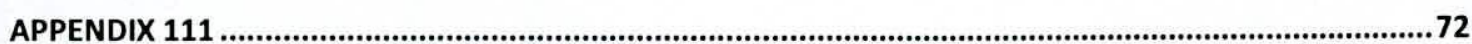




\section{LIST OF TABLES}

TABLE 2.1.Essential Amino Acids (Percentage) In Various Proteins

TABLE 3.1.Sequence Of Serial Dilution.

TABLE 4.1.Proximate analysis of untreated and marinated shark during storage of three months.

TABLE 4.2 .Moisture content of marinated and dried fish sample during storage of three months.

TABLE 4.3.TMA content of marinated fish samples during storage of three months.

TABLE 4.4 Total microbial count of fresh fish sample during storage of three months.

TABLE 4.5 Total microbial count of marinated and dried sample during storage of three months.

TABLE 4.6 Total microbial count of marinated and chilled sample during storage of three months. . .58

TABLE 4.7 Total microbial count of marinated and frozen sample during storage of three months. 


\section{LIST OF FIGURES}

Figure2.1: Shark production vs. total large pelagic fish production...................7

Figure 2.2. Photo of Squalus megalops..........................................11

Figure 2.3. Geographical distribution...................................... 12

Figure 4.1. Moisture contents of the dried fish during the storage of 3 months.........54

Figure 4.2. TMA contents of the dried fish during the storage of 3 months...........56

Figure 4.3 TMA content of Marinated and frozen fish during 3 months of storage........57

Figure 4.4 TMA content of Marinated and chilled fish during 3 months of storage......58

Figure 4.5 Marinated and frozen shark sample...................................63 


\section{ACKNOWLEDGEMENT}

I would like to express my sincere thanks to my supervisors, Dr. (Mrs.) Indira Wickramasinghe, Head of Department of Food science and Technology, Faculty of Applied Sciences, University of Sri Jayawardenapura and Professor. Arthur Bamunuarachchi, Department of Food science and Technology, Faculty of Applied sciences, University of Sri Jayawardenapura, for their guidance, advice and encouragement throughout the period of study to complete it successfully.

Also my thanks go to Prof. K.K.D.S. Ranaweera, the Coordinator MSc in Food science and Technology, for helping me throughout this research work and for the advice given to me regarding my research.

My special thanks are due to Mrs. Rupika Perera, Assistant Coordinator M.Sc in Food science and Technology prgrame, Department of Food Science and technology, Faculty of Applied Sciences, University of Sri Jayawardenapura. Also I would like to take this opportunity to thanks all the members of the laboratory staff in the department of Food science and Technology for the help given.

I am also indebted to my colleagues of the M.Sc course in Food science and Technology who encouraged and helped in many ways. I also thank my friends and family members and all others too, who helped me in my research in various ways. 


\section{ABBREVIATIONS}

${ }^{0} \mathrm{C} \quad$ degree of Celsius

g gram

L Liter

$\mathrm{ml}$ milliliter

$\% \quad$ percent

$\mu \mathrm{m} \quad$ micrometers

CFU Colony Forming Units

min minutes

NA Nutrient Agar

$\mathrm{H}_{2} \mathrm{SO}_{4} \quad$ Sulphuric acid

$\mathrm{HCl} \quad$ Hydrochloric acid 
Marination and post marination storage of shark

By

Merita Joseph

\begin{abstract}
Fish has been one of the main foods for humans for many centuries and still constitutes an important part of the diet in many countries. The advantages of fish as a food is due to easy digestibility and high nutritional value. Sharks are a valuable resource. Sharks are commonly termed fish, even though they are only distantly related to the classical (bony) fish. Shark fin is eaten by people around the world and it is very popular. Fishermen harvest the shark in the sea and remove the fins and throw the flesh back to the sea or sell the shark flesh for low price. The reason for this is the bulky body of sharks and it's low market value due to the urea smell.
\end{abstract}

Hence, this study was undertaken to evaluate the possibility of utilizing the flesh of the shark and increase its market value by reducing the smell and also to increase the shelf life of shark flesh as food. Marination is one of the best methods to reduce the smell and to increase the shelf life of the shark flesh.

The process involves marinating the shark in vinegar and spices. In this study shark fleshes were immersed in a mixture of vinegar and spices for 12 hours, so the spices and vinegar can penetrate to into the fleshes. After 12 hours one portion of shark flesh was dried for 36 hours another portion was kept in refrigerator $\left(4^{\circ} \mathrm{C}\right)$ and third portion was kept in the freezer $\left(-18^{\circ} \mathrm{C}\right)$. 
The samples were subjected to chemical and microbiological analyses during the storage period. Sensory evaluation was also done at the end of the storage period.

The moisture content gradually increased during the storage period. The moisture content of the fresh fish was $78.96 \%$, after marination it was $70 \%$. The moisture content of the fresh fish was $82 \%$ after three months, it exceeded the critical limit.

The histamine content gradually increased during the storage period. According to the results the histamine content of dried fish after three months was 7.1ppm, chilled fish 8.7 $\mathrm{ppm}$ and the frozen fish 8ppm. The values did not exceed the critical limit of $30 \mathrm{ppm}$ (http://www.fda.gov/ICECI/EnforcementActions/WarningLetters/2013/ucm374636.htm). Histamine content of the untreated sample was 33ppm. It exceeded the critical limit.

Trimethylamine content of the marinated and untreated fish samples were determined during the storage period. According to the results the TMA of marinated and dried fish was $19.4 \mathrm{mg} / 100 \mathrm{~g}$, marinated and chilled fish was $19.9 \mathrm{mg} / 100 \mathrm{~g}$ and marinated and frozen fish was $19.1 \mathrm{mg} / 100 \mathrm{~g}$. These results did not exceed the critical limit of $26 \mathrm{mg} / 100 \mathrm{~g}$ (Journal of the Fisheries Research Board of Canada, 1945). So they are safe for consumption after three months. But the TMA content of the untreated fish after three months was $30 \mathrm{mg} / 100 \mathrm{~g}$, which is unsafe for consumption.

Microbial analysis was done on untreated and marinated fish samples. The microbial count for marinated and dried fish after three months was $8.2 \times 10^{3}$, marinated and chilled fish $3.1 \times 10^{5}$ and marinated and frozen fish was $5.2 \times 10^{4}$. The results showed that, the microbial content was in the acceptable range. But the microbial count of untreated sample was not in the acceptable range. 
Sensory evaluation is used in the testing of fishery products for conformity requirements. Four types of samples (fresh fish, marinated and dried fish, marinated and chilled fish, marinated and frozen fish) were steamed and kept for evaluation. Twenty assessors evaluated the sample. From the results of evaluation statistical analysis was done.

According to Kruskal-wallis test results the $\mathrm{P}$ values for taste, texture and odour are $\mathrm{P}=$ $0.000, \mathrm{P}=0.000$ and $\mathrm{P}=0.000$ respectively. There exists enough evidence to conclude that there is a difference in the median test scores (and, hence, the mean test scores) among the four methods based. According to Mann-Whitney test the untreated sample and the marinated samples show significant difference in taste, texture and odour. But the marinated samples did not show any significant difference among them. Since the pvalue is not less than the chosen $\alpha$ level of 0.05 , in the marinated samples there is insufficient evidence to reject $\mathrm{H}_{0}$.

According to all results obtained from chemical, biological and sensory evaluation the perceptible Organoleptic properties of these types of marinated fishes are acceptable. Also the odour of fresh flesh of shark is very much reduced and the flavour is increased by this method. So these types of products can be marketable and consumable within three months. 


\section{CHAPTER 1}

\section{INTRODUCTION}

Fish has been one of the main foods for humans for many centuries and still constitutes an important part of the diet in many countries. The advantages of fish as a food are its easy digestibility and high nutritional value. Since $70 \%$ of the Earth's surface is covered by water, there are plenty of sources to harvest fish. The range of fish products is very large and includes foods prepared using a broad spectrum of both traditional and modern food technologies. Fish and seafood products are some of the most important protein sources in human nutrition. At the same time these products are highly perishable and if left unpreserved, spoil rapidly. Fish is favored over meat is because fish has omega-3fatty acid. And also it reduces the risk of cholesterol and some heart diseases. Many pelagic fish species have adequate content of protein, fat and acceptable amount of nutrition (Kannaiyan 1980).

Sharks are a valuable resource. Sharks are commonly termed fish, even though they are only distantly related to the classical (bony) fish (Schubring, 2007). Shark fin is eaten by people around the world and it is very popular. So when a shark is caught, its fins are cut off and the body is thrown back into the sea, often while the shark is alive. Unable to swim the shark slowly sinks toward the bottom where it suffocates or is eaten alive by other fish. Fishermen do not specifically target sharks for capture, but normally catch them as bycatch, with the more important targeted bony species. Once caught however, the sharks are not discarded, but are brought back whole to the port where the meat is sold for a low price and the fins sold at a much higher price due to their higher demand. The smaller species of sharks are generally used as sources of fresh, chilled, or frozen meat, while the larger sharks provide fins and hides. But, shark product preservation including drying is still limited (Ali et al., 1999). Sometimes Shark Finning takes place at sea, so only the fins have to be transported back to land. Shark meat is considered low value because of the urea smell and therefore not worth the cost of transporting the bulky shark bodies to market. 
There are numerous species of fish caught annually throughout the world but they are not all necessarily commercially important (Yapar et al., 2006). However, from the economic and nutritional standpoints, it is essential to utilize the entire catch for human consumption.

One of the objectives of this project is to utilize the flesh of the shark and increase its market value by reducing the smell. Another objective of this project is to increase the shelf life of shark. Marination is one of the best methods to reduce the smell and to increase the shelf life of the shark flesh.

Sharks have high urea and trimethylamine in the blood and tissues, substances that help sharks to maintain their osmotic balance. According to Gordievskaya, Sharks have various urea concentrations which are species characteristic. And Urea is not dangerous but it gives the mat a particular smell and a somewhat bitter and acid taste. This affects either the choice of species for human consumption or the processing techniques. With the difference in the urea concentration, the intensity of the smell and taste differs between species. Accordingly some species need a more through treatment than others, in order to reduce the urea content. Urea must be removed by bleeding the shark immediately after capture. If this is not promptly done, the urea will degrade into ammonia which will contaminate the shark's flesh. Urea is a non-toxic by product of protein Metabolism which is formed in the blood and body fluid of all marine fish both bony and cartilaginous. The only difference is that the bony fish excrete urea quickly while sharks retain it in their blood. As a result the blood of shark has a higher osmotic concentration than that of the bony fish and absorbs fresh water through membranes by osmosis. The intensity of Urea varies by age and species. Accordingly some species need a more through treatment than others, in order to reduce the urea content. 